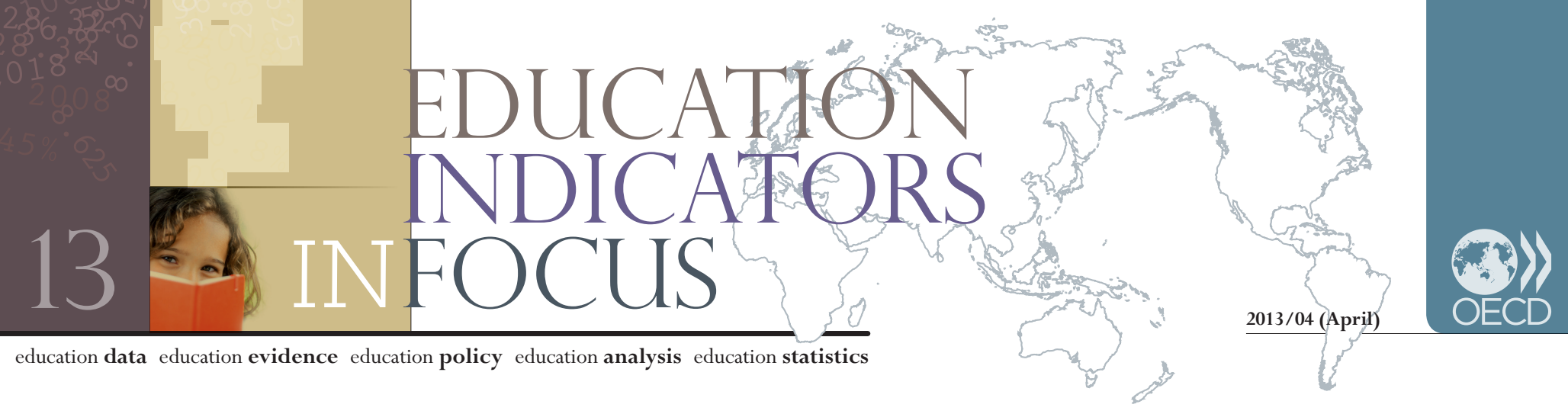

\title{
How difficult is it to move from school to work?
}

- In some countries, an increasing number of young people are neither in employment, nor in education or training (NEET). A high proportion of NEETs is an indicator of a difficult transition between school and work.

- Higher educational attainment eases the transition into employment.

- Demographic changes, economic conditions and cultural gender role expectations affect the transition process. But flexible school-work arrangements can have a positive impact on the transition to employment.

Having few individuals who are neither in employment, nor in education or training is a sign of a healthy transition from school to work.

Moving from school to work is a very important transition in the life of young people. For many of them the move is not always successful, and many hindrances can hamper a smooth transition. The economic conditions naturally have a significant impact, but institutional arrangements in the education system and the labour market also play a role. The combined effect is that a number of people end up falling into the gap between school and work. The proportion of young people who are neither in employment, nor in education and training (the so-called "NEET population") is a good indicator of the size of the population at risk. A low proportion of NEETs in the relevant age cohort can be seen as a marker of the smoothness of the transition.

The unemployment rate is a commonly used labour market measure. However, among young people, unemployment rates can provide a distorted picture of the situation. A large proportion of the population between the ages of 15 and 29 will be in education or training, rather than in the labour force. It is therefore more appropriate to measure the proportion who are NEET, as it takes the impact of education and training levels into account.

Education and employment among 15-29 year-olds in 2011 (\%)

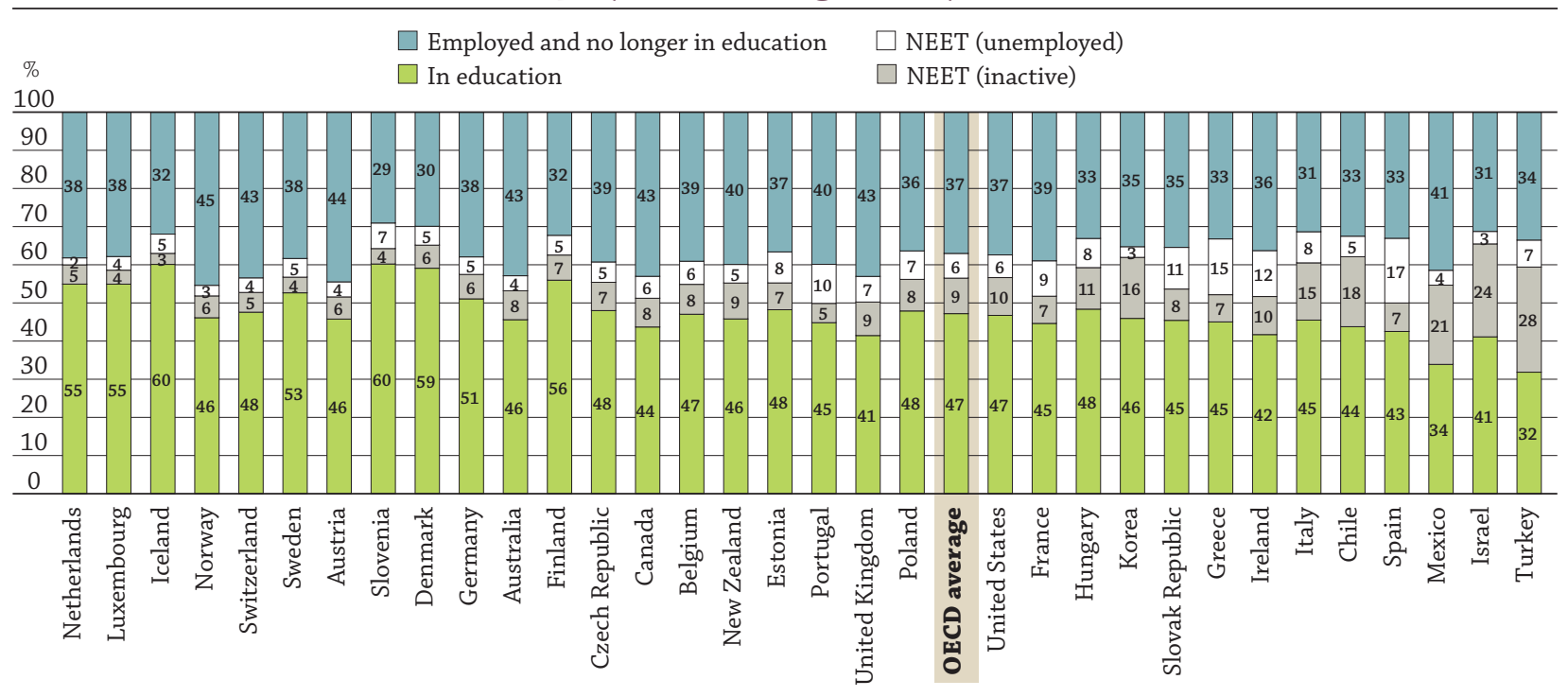

Countries are ranked in ascending order of population neither in employment nor in education (NEET).

Source: OECD, Education at a Glance 2013: OECD Indicators, Indicator C5 (www.oecd.org/edu/eag.htm), to be released 2013, 25th June. 
The figures can be further broken down into those who are looking for work ("unemployed") and those who are no longer looking for work ("inactive").

In $2011,47 \%$ of $15-29$ year-olds were in education or training across the OECD and $37 \%$ were working. The remaining 16\% were NEET, broken down into 6.5\% unemployed and $9.3 \%$ inactive, i.e. not looking for a job. In

Austria, Iceland, Luxembourg, the Netherlands, Norway, Sweden and Switzerland, less than 10\% of young people were NEET, suggesting a smooth transition process. The highest rates are to be found in Chile, Greece, Ireland, Israel, Italy, Mexico, Spain and Turkey, all with over $20 \%$ of young people neither working nor in education.

Among the youngest age group, the 15-19 year-olds, a high NEET population is particularly concerning. Although a growing share of young people are staying in education beyond the compulsory schooling age, some leave the education system prematurely. A high number of them may not even have completed their upper secondary education and are particularly vulnerable. They are less likely to be reintegrated into the labour market, with long-term effects on their future employment and earning prospects. There is also a significant public cost associated with high levels of these very young NEETS, in terms of long-term unemployment costs, loss of human capital and foregone tax revenues for national economies.

In 2011, an average of $86 \%$ of $15-19$ year-olds were in education or training across the OECD countries, $6 \%$ were in employment, but $8 \%$ were neither working nor studying. While less than $3 \%$ were unemployed and looking for work, almost $6 \%$ were inactive, effectively out of the labour force.

\section{Transition from school to work is smoother for young people who have completed higher education.}

The size of the NEET population is affected by the level of education completed. More educated people are less likely to be neither in employment, nor in education (NEET).

\section{Distribution of 15-29 year-olds by completed level of educational attainment (2011)}

\begin{tabular}{|c|c|c|c|c|c|c|c|}
\hline \multirow{3}{*}{$\begin{array}{l}\text { Completed } \\
\text { education }\end{array}$} & \multirow[b]{2}{*}{ IN EDUCATION } & \multicolumn{5}{|c|}{ NO LONGER IN EDUCATION } & \\
\hline & & $\begin{array}{c}\text { NEETS } \\
\text { (Unemployed) }\end{array}$ & $\begin{array}{l}\text { NEETS } \\
\text { (Inactive) }\end{array}$ & Employed & $\begin{array}{c}\text { Percentage } \\
\text { of unemployed individuals }\end{array}$ & $\begin{array}{c}\text { Percentage } \\
\text { of inactive individuals }\end{array}$ & \\
\hline & (1) & (2) & (3) & (4) & $(2) /(2+3+4)$ & $(3) /(2+3+4)$ & \\
\hline $0 / 1 / 2$ & 67.5 & 5.7 & 10.1 & 16.7 & $18 \%$ & $31 \%$ & 100 \\
\hline $3 / 4$ & 40.9 & 7.0 & 9.2 & 42.9 & $12 \%$ & $15 \%$ & 100 \\
\hline $5 / 6$ & 23.2 & 6.7 & 6.6 & 63.6 & $9 \%$ & $9 \%$ & 100 \\
\hline Total & 47.2 & 6.5 & 9.3 & 37.0 & $12 \%$ & $18 \%$ & 100 \\
\hline
\end{tabular}

\section{Transition from school to work is facilitated by flexible school-work arrangements.}

Transition from school to work may also be affected by the institutional arrangements between schooling and work. In some countries, schooling and working mainly occur consecutively, with full-time education being followed

by full-time work, while in other countries they are concurrent. Many countries, particularly in Europe, offer work-study programmes at the upper secondary and post-secondary non-tertiary levels of education. These provide structured vocational education routes to recognised occupational qualifications. In other countries, education and work are rarely combined in this way. In the past, the transition between education and work has typically been smoother in countries with work-study programmes than those without. In the current crisis period, however, the relative advantage of those countries has weakened. Australia, Austria, Belgium, the Czech Republic, Germany, Italy, the Slovak Republic, Switzerland and the United Kingdom offer work-study programmes at these levels of education, although participation in Belgium and Italy is somewhat lower than in the other countries. In 2011, these countries performed slightly better on average than the OECD overall in some measures but not all. Their employment-to-population ratio among young people was higher, but the unemployment ratio was almost the same. In 2011, almost 47\% of 15-29 year-olds in countries offering work-study programmes were in education or training, the same as the OECD average; $40 \%$ were in employment (against 37\% for the OECD overall). Work-study programme countries had a 14\% NEET rate against $16 \%$ for the OECD as a whole. 


\section{EDUCATION INDICATORS IN FOCUS}

Transition from school to work is affected by cultural role expectations.

Expectations regarding gender roles and family formation seem to have a particularly strong impact on the transition process, especially for women.

On average across OECD countries, young women are more likely to be NEET than men: 18\% of 15-29 year-old women, compared to $13 \%$ of men.

\section{Percentage of 15-29 year-olds neither in employment nor in education (NEET), by gender (2011)}

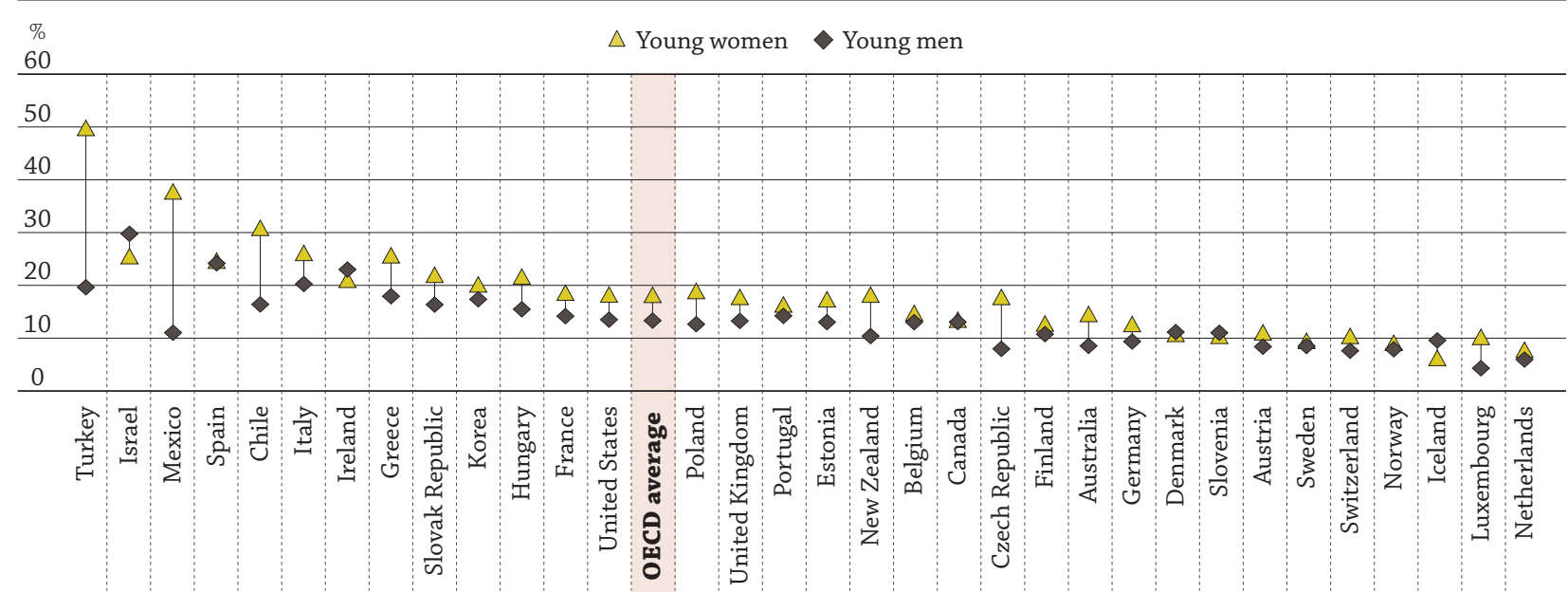

Countries are ranked in descending order of the proportion of 15-29 year olds neither in employment nor in education (NEET) in 2011. Source: OECD, Education at a Glance 2013: OECD Indicators, Indicator C5 (www.oecd.org/edu/eag.htm), to be released 2013, 25th June.

In Turkey, women are twice as likely as men to be NEET. In Mexico, the gender gap is even wider: young Mexican women are three times more likely than young Mexican men to be NEET. These disparities may be related to social expectations since probably these young women have decided to start a family rather than to pursue a career.

In Israel, the gender gap is narrow. Some young women leave the labour market for family reasons, but the military service is a more important factor. Military conscripts are included in the data as inactive, boosting the inactivity rate for 18-21 year-old men and for 18-19 year-old women.

Trends in the distribution of 15-29 year-olds between 1997 and 2011 on average across the OECD countries

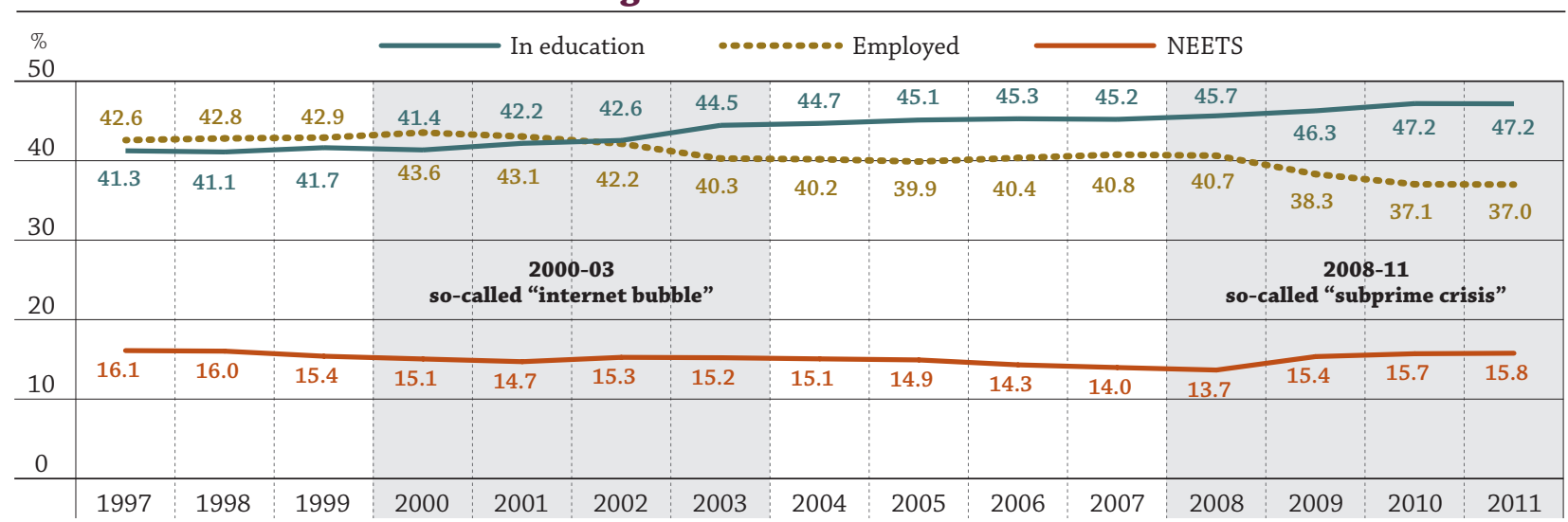

Source: OECD, Education at a Glance 2013: OECD Indicators, Indicator C5 (www.oecd.org/edu/eag.htm), to be released 2013, 25th June. 
Transition from school to work is affected by the economic conditions.

During economic downturns, high unemployment rates make the transition from school to work substantially more difficult. Young people leaving education experience greater difficulty finding jobs and those in work are more likely to lose their jobs than their older and more experienced peers. The employment-to-population ratio and the NEET ratio follow the economic cycle.

Unfavourable labour market conditions give young people an incentive to stay longer in education as high unemployment rates drive down the opportunity costs of education. In other words, if there is no work for young and inexperienced people, it's better for them to invest more in education and then to seek work with a higher educational qualification. A higher qualification increases individuals' employability.

\section{Impact of demographic change on education participation ratios between 2004 and 2011 (\%)}

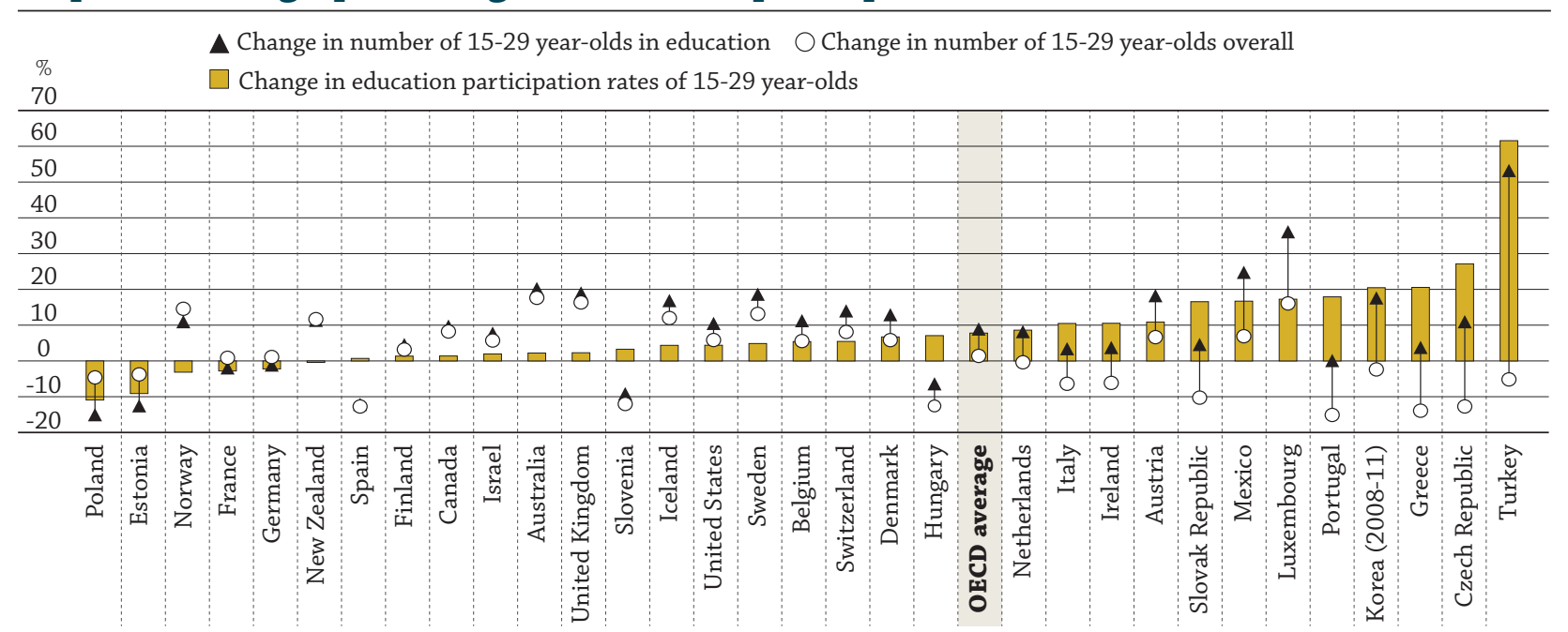

Countries are ranked in ascending order of population neither in employment nor in education (NEET).

Source: OECD, Education at a Glance 2013: OECD Indicators, Indicator C5 (www.oecd.org/edu/eag.htm), to be released 2013, 25th June.

Transition from school to work is affected by demographic changes.

The ageing of the population and the declining size of the youth population in OECD countries should favour employment among young adults. However, poor general labour market conditions during the crisis and its aftermath have resulted in a substantially more difficult transition for the younger population. The positive impact of the current demographic trends should be felt as soon as the economy recovers.

Furthermore, changes in the total population of 15-29 year-olds may distort the picture of participation in education. In the Czech Republic, Estonia, Greece, Hungary, Ireland, Italy, the Netherlands, Poland, Portugal, the Slovak Republic, Slovenia, Spain and Turkey, a shrinking population of 15-29 year-olds has contributed to improving the relative participation of young people in education.

\section{The bottom line A more or less successful transition from school to work is the combined} result of contextual factors such as demographic changes, the economic conditions or cultural role expectations, but also of specific school-work arrangements. In general, the transition is smoother in countries with flexible school-work arrangements.

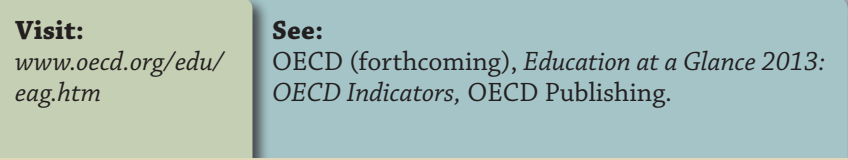

For more information, contact:

Karinne Logez

(Karinne.Logez@oecd.org)
Coming next month:

International mobility:

Where do international students go

to study and what are the main trends? 